\title{
Diffuse Optical Spectroscopy Assessment of Resting Oxygen Metabolism in the Leg Musculature
}

\author{
Scott E. Boebinger ${ }^{1}$, Rowan O. Brothers ${ }^{1}$, Sistania Bong ${ }^{1}$, Bharat Sanders ${ }^{1}$, Courtney McCracken ${ }^{2}$, \\ Lena H. Ting ${ }^{1,3}$ and Erin M. Buckley ${ }^{1,4,5, *}$ \\ 1 Wallace H. Coulter Department of Biomedical Engineering, Georgia Institute of Technology, Emory University, \\ Atlanta, GA 30332, USA; sboebin@emory.edu (S.E.B.); rowan.oakley.brothers@emory.edu (R.O.B.); \\ sistaniameilina@gmail.com (S.B.); bharat.sanders@gmail.com (B.S.); lting@emory.edu (L.H.T.) \\ 2 Center for Research and Evaluation, Kaiser Permanente of Georgia, Atlanta, GA 30309, USA; \\ courtney.e.mccracken@kp.org \\ 3 Department of Rehabilitation Medicine, Division of Physical Therapy, Emory University, \\ Atlanta, GA 30322, USA \\ 4 Department of Pediatrics, School of Medicine, Emory University, Atlanta, GA 30322, USA \\ 5 Children's Healthcare of Atlanta, Children's Research Scholar, Atlanta, GA 30322, USA \\ * Correspondence: erin.buckley@emory.edu
}

Citation: Boebinger, S.E.; Brothers, R.O.; Bong, S.; Sanders, B.;

McCracken, C.; Ting, L.H.; Buckley, E.M. Diffuse Optical Spectroscopy Assessment of Resting Oxygen Metabolism in the Leg Musculature. Metabolites 2021, 11, 496. https:// doi.org/10.3390/metabo11080496

Academic Editor: Wesley Baker

Received: 17 July 2021

Accepted: 27 July 2021

Published: 29 July 2021

Publisher's Note: MDPI stays neutral with regard to jurisdictional claims in published maps and institutional affiliations.

Copyright: (c) 2021 by the authors. Licensee MDPI, Basel, Switzerland. This article is an open access article distributed under the terms and conditions of the Creative Commons Attribution (CC BY) license (https:// creativecommons.org/licenses/by/ $4.0 /)$.

\begin{abstract}
We lack reliable methods to continuously assess localized, resting-state muscle activity that are comparable across individuals. Near-infrared spectroscopy (NIRS) provides a low-cost, noninvasive means to assess localized, resting-state muscle oxygen metabolism during venous or arterial occlusions $\left(\mathrm{VO}_{2} \mathrm{VO}\right.$ and $\mathrm{VO}_{2 \mathrm{AO}}$, respectively). However, this technique is not suitable for continuous monitoring, and its utility is limited to those who can tolerate occlusions. Combining NIRS with diffuse correlated spectroscopy (DCS) enables continuous measurement of an index of muscle oxygen metabolism $\left(\mathrm{VO}_{2 \mathrm{i}}\right)$. Despite the lack of previous validation, $\mathrm{VO}_{2 \mathrm{i}}$ is employed as a measure of oxygen metabolism in the muscle. Here we characterized measurement repeatability and compared $\mathrm{VO}_{2 \mathrm{i}}$ with $\mathrm{VO}_{2} \mathrm{VO}$ and $\mathrm{VO}_{2 \mathrm{AO}}$ in the medial gastrocnemius (MG) in 9 healthy adults. Intra-participant repeatability of $\mathrm{VO}_{2 \mathrm{i}}, \mathrm{VO}_{2} \mathrm{VO}$, and $\mathrm{VO}_{2 \mathrm{AO}}$ were excellent. $\mathrm{VO}_{2 \mathrm{i}}$ was not significantly correlated with $\mathrm{VO}_{2 \mathrm{AO}}(p=0.15)$ nor $\mathrm{VO}_{2 \mathrm{VO}}(p=0.55)$. This lack of correlation suggests that the variability in the calibration coefficient between $\mathrm{VO}_{2 \mathrm{i}}$ and $\mathrm{VO}_{2 \mathrm{AO}} / \mathrm{VO}_{2} \mathrm{VO}$ in the $\mathrm{MG}$ is substantial across participants. Thus, it is preferable to calibrate $\mathrm{VO}_{2 \mathrm{i}}$ prior to every monitoring session. Important future work is needed to compare $\mathrm{VO}_{2 \mathrm{i}}$ against gold standard modalities such as positron emission tomography or magnetic resonance imaging.
\end{abstract}

Keywords: near-infrared spectroscopy; diffuse correlation spectroscopy; muscle; oxygen metabolism; blood flow

\section{Introduction}

Tonic muscle activity, defined as the baseline, resting-state level of electrical and/or metabolic muscle activity, is affected by numerous disease states, including Parkinson's disease [1] and cerebral palsy [2]. However, reliable methods to assess localized tonic muscle activity are lacking. Currently, tonic muscle activity is typically evaluated using a subjective assessment that involves rating the resistance of the joint during passive movement of a limb [3,4]. Other indirect mechanical metrics such as the torque required to move the limb have also been used [5,6]. Direct measures of the muscle itself via magnetic resonance spectroscopy (MRS) and/or positron emission tomography (PET) can provide high spatial resolution images of muscle metabolic activity; however, these techniques often require exogenous contrast agents, are costly, and are unable to provide continuous measures [7]. Indirect calorimetry provides continuous measures of wholebody oxygen metabolism throughout the respiratory cycle [8,9]; however, this method is not localized to a muscle of interest. Similarly, blood samples provide measures of 
whole-limb metabolism that, while more localized than indirect calorimetry, are not highly localized [10]. Alternatively, electromyography (EMG) measures of electrical activity provide a more localized measure of muscle activity; however, EMG requires normalization to its resting level or maximum voluntary contraction level which hinders its ability to assess tonic muscle activity $[1,11]$. Additionally, EMG is susceptible to variations in adipose tissue thickness [12,13] and skin impedance [14] and therefore tonic muscle activity measured with EMG should not be compared across different measurement sessions nor compared between individuals [11]. Finally, near-infrared spectroscopy (NIRS) provides a low-cost, non-invasive means to assess resting-state regional muscle oxygen metabolism and blood flow via a brief vascular occlusion [15-26]. While this optical approach is relatively simple to perform and the quantitative values can be compared across individuals, it is not suitable for continuous monitoring, and its utility is limited to patients who can tolerate occlusion.

The combination of NIRS with diffuse correlation spectroscopy (DCS) offers an alternative low-cost, non-invasive optical approach to continuously $(\sim 1 \mathrm{~Hz})$ estimate an index of muscle oxygen metabolism without the need for vascular occlusion [15,16,26-32]. In this hybrid approach, oxygen extraction fraction (OEF) measured with NIRS is combined with an index of blood flow (BFI) measured with DCS to yield an index of muscle oxygen metabolism $\left(\mathrm{VO}_{2 \mathrm{i}}\right)$ via Fick's law. Although $\mathrm{VO}_{2 \mathrm{i}}$ has been reported by several research groups $[15,16,27,32]$, validation in the muscle has been limited to a single comparison with measures of whole limb metabolism [27].

Herein we compare continuous NIRS + DCS measures of BFI and $\mathrm{VO}_{2 \mathrm{i}}$ in the medial gastrocnemius (MG) muscle to NIRS-only measures of blood flow during venous occlusion and oxygen metabolism during venous and arterial occlusions. Moreover, we characterize the repeatability of each approach. We hypothesize that the DCS-measured BFI in the calf would be correlated to the NIRS-measured blood flow obtained via venous occlusion (as previously shown in the forearm [33]). Further, we hypothesized that the NIRS + DCS measured $\mathrm{VO}_{2 \mathrm{i}}$ would be correlated with NIRS-only measures of mean oxygen metabolism obtained during either a venous or arterial occlusion.

\section{Results}

A total of 9 participants were recruited for this study ( 5 female, $27 \pm 6$ years). One participant only completed a single arterial occlusion due to time constraints; three arterial occlusions from another participant were discarded because the slope of the difference between oxy- and deoxyhemoglobin $(\mathrm{HbD})$ increased during occlusion; DCS data from another participant was discarded due to technical difficulties with the laser during acquisition; and NIRS data from a single epoch of one participant was also discarded due to issues with writing data to file. The remaining datasets were all included for analysis.

Table 1 outlines the mean \pm standard deviation (SD) NIRS-measured resting-state optical properties, hemoglobin concentrations, and oxygen saturation for each participant. Cohort averaged resting-state total hemoglobin concentration $\left(\mathrm{HbT}_{0}\right)$ was $48.1 \pm 18.2 \mu \mathrm{M}$ and oxygen saturation $\left(\mathrm{StO}_{20}\right)$ was $55.5 \pm 9.9 \%$. Similarly, Table 2 reports the mean $\pm \mathrm{SD}$ NIRS-measured $\mathrm{VO}_{2 \mathrm{AO}}, \mathrm{VO}_{2} \mathrm{VO}$, and $\mathrm{BF}$ along with DCS-measured BFI and NIRS + DCSmeasured $\mathrm{VO}_{2 \mathrm{i}}$ for each participant along with group averages. $\mathrm{VO}_{2 \mathrm{i}}$ averaged prior to the venous occlusion was not statistically significantly different from $\mathrm{VO}_{2 \mathrm{i}}$ averaged prior to the arterial occlusion; therefore, only mean \pm standard deviation of $\mathrm{VO}_{2 \mathrm{i}}$ prior to arterial occlusion was reported. Although $\mathrm{BF}, \mathrm{VO}_{2 \mathrm{AO}}$, and $\mathrm{VO}_{2} \mathrm{VO}$ were measured at 4 source-detector separations, data is reported from $3.5 \mathrm{~cm}$, which was consistently higher than the other separations (all $p<0.05$ ). There were no statistically significant differences in any of the parameters reported in Tables 1 and 2 between sexes. Excellent intra-participant repeatability was observed for $\mathrm{VO}_{2 \mathrm{AO}}, \mathrm{VO}_{2} \mathrm{VO}, \mathrm{VO}_{2 \mathrm{i}}, \mathrm{BF}, \mathrm{HbT}_{0}$, and $\mathrm{StO}_{20}$ as indicated by ICC > 0.75; BFI repeatability was rated good (ICC $=0.62$, Table 3 ). Coefficient of variation $(\mathrm{CV})$ was $<0.27$ for all measured parameters, with $\mathrm{HbT}_{0}$ and $\mathrm{StO}_{20}$ demonstrating the least amount of variation (mean $\mathrm{CV}=0.06$ and 0.03 , respectively). ICC values for $\mathrm{VO}_{2 \mathrm{AO}}$, 
$\mathrm{VO}_{2 \mathrm{VO}}$, and $\mathrm{BF}$ were highest and $\mathrm{CV}$ values were lowest at the $3.5 \mathrm{~cm}$ source-detector separation; however, regardless of separation, all parameters had ICC $>0.49$ and $\mathrm{CV}<0.27$ (Supplementary Table S2).

Table 1. Resting-state optical properties and hemoglobin concentrations. Mean \pm standard deviation of resting-state absorption and reduced scattering coefficients $\left(\mu_{\mathrm{a} 0}\right.$ and $\mu_{\mathrm{s} 0}{ }^{\prime}$, respectively) at $852 \mathrm{~nm}, \mu_{\mathrm{s} 0}$ ' scaling factor (A) and scattering power (b), as well as oxy- and deoxy-hemoglobin concentrations $\left(\mathrm{HbO}_{0}\right.$ and $\mathrm{HbR}_{0}$, respectively), total hemoglobin concentration $\left(\mathrm{HbT}_{0}\right)$, and oxygen saturation $\left(\mathrm{StO}_{20}\right)$ for each participant across 11 repetitions. Group averaged results are shown in the bottom row.

\begin{tabular}{|c|c|c|c|c|c|c|c|c|}
\hline Participant & $\mu_{\mathrm{a} 0}\left(\mathrm{~cm}^{-1}\right)$ & $\mu_{\mathrm{s} 0^{\prime}}\left(\mathrm{cm}^{-1}\right)$ & A & $\mathbf{b}$ & $\mathrm{HbO}_{0}(\mu \mathrm{M})$ & $\mathrm{HbR}_{0}(\mu \mathrm{M})$ & $\mathrm{HbT}_{0}(\mu \mathrm{M})$ & $\mathrm{StO}_{20}(\%)$ \\
\hline 1 & $0.163 \pm 0.008$ & $6.61 \pm 0.66$ & $485 \pm 1322$ & $0.22 \pm 0.34$ & $33.5 \pm 2.9$ & $25.7 \pm 2.6$ & $59.1 \pm 3.4$ & $56.6 \pm 3.6$ \\
\hline 2 & $0.159 \pm 0.001$ & $5.34 \pm 0.14$ & $178 \pm 130$ & $0.41 \pm 0.27$ & $34.2 \pm 0.6$ & $22.1 \pm 0.7$ & $56.3 \pm 0.4$ & $60.8 \pm 1.1$ \\
\hline 3 & $0.157 \pm 0.004$ & $5.71 \pm 0.12$ & $345 \pm 154$ & $0.59 \pm 0.08$ & $31.57 \pm 1.6$ & $24.7 \pm 1.8$ & $56.3 \pm 2.0$ & $56.1 \pm 2.4$ \\
\hline 4 & $0.122 \pm 0.004$ & $6.00 \pm 0.40$ & $445 \pm 238$ & $0.58 \pm 0.20$ & $26.1 \pm 1.4$ & $13.3 \pm 0.5$ & $39.4 \pm 1.8$ & $66.2 \pm 0.6$ \\
\hline 5 & $0.146 \pm 0.003$ & $8.03 \pm 0.39$ & $134 \pm 78$ & $0.39 \pm 0.10$ & $29.9 \pm 1.0$ & $20.9 \pm 0.7$ & $50.8 \pm 1.3$ & $58.9 \pm 1.1$ \\
\hline 6 & $0.127 \pm 0.025$ & $6.74 \pm 1.18$ & $14 \pm 13$ & $0.11 \pm 0.10$ & $25.9 \pm 7.6$ & $16.2 \pm 2.8$ & $42.1 \pm 10.5$ & $61.2 \pm 2.9$ \\
\hline 7 & $0.205 \pm 0.007$ & $5.86 \pm 0.15$ & $216 \pm 76$ & $0.53 \pm 0.05$ & $46.5 \pm 2.1$ & $30.5 \pm 1.2$ & $77.0 \pm 3.1$ & $60.4 \pm 0.8$ \\
\hline 8 & $0.061 \pm 0.001$ & $4.71 \pm 0.06$ & $11 \pm 5$ & $0.12 \pm 0.07$ & $4.5 \pm 0.3$ & $9.7 \pm 0.3$ & $14.2 \pm 0.3$ & $31.4 \pm 1.8$ \\
\hline 9 & $0.109 \pm 0.003$ & $5.68 \pm 0.18$ & $21 \pm 6$ & $0.19 \pm 0.04$ & $17.9 \pm 0.6$ & $17.3 \pm 1.1$ & $35.2 \pm 1.6$ & $50.9 \pm 1.2$ \\
\hline Group & $0.139 \pm 0.041$ & $6.02 \pm 1.00$ & $218 \pm 469$ & $0.37 \pm 0.24$ & $27.9 \pm 1$ & $20.3 \pm 6.5$ & $48.1 \pm 18.2$ & $55.5 \pm 9.9$ \\
\hline
\end{tabular}

Table 2. Resting-state oxygen metabolism and blood flow. Mean \pm standard deviation oxygen metabolism measured during arterial occlusion and venous occlusion $\left(\mathrm{VO}_{2 \mathrm{AO}}\right.$ and $\mathrm{VO}_{2 \mathrm{VO}}$, respectively), as well as oxygen metabolism index averaged prior to the arterial occlusion $\left(\mathrm{VO}_{2 \mathrm{i}}\right.$, in units of $\left.\mathrm{cm}^{2} / \mathrm{s} \times \mathrm{mL} \mathrm{O}_{2} / \mathrm{g} \times 10^{-8}\right)$, blood flow measured during venous occlusion (BF), and blood flow index (BFI, in units of $\mathrm{cm}^{2} / \mathrm{s} \times 10^{-7}$ ) across 5 repetitions. NA denotes data not available. Participant 6 only completed 1 arterial occlusion, and therefore no $\mathrm{VO}_{2} \mathrm{VO}, \mathrm{BF}$, or BFI values; participant 7 had no DCS data and therefore no $\mathrm{VO}_{2 \mathrm{i}}$ or $\mathrm{BFI}$ values. $\mathrm{VO}_{2 \mathrm{AO}}, \mathrm{VO}_{2 \mathrm{VO}}, \mathrm{VO}_{2 \mathrm{i}}$, and $\mathrm{BF}$ data are reported for the $3.5 \mathrm{~cm}$ source-detector separation.

\begin{tabular}{|c|c|c|c|c|c|}
\hline Participant & $\begin{array}{c}\mathrm{VO}_{2 \mathrm{AO}} \\
\left(\mathrm{mLO}_{2} / \mathrm{min} / 100 \mathrm{~g}\right)\end{array}$ & $\begin{array}{c}\mathrm{VO}_{2 \mathrm{VO}} \\
\left(\mathrm{mLO}_{2} / \mathrm{min} / 100 \mathrm{~g}\right)\end{array}$ & $\mathrm{VO}_{2 \mathrm{i}}(\mathrm{au})$ & $\mathrm{BF}(\mathrm{mL} / \mathrm{min} / 100 \mathrm{~mL})$ & BFI $\left(\times 10^{-7} \mathrm{~cm}^{2} / \mathrm{s}\right)$ \\
\hline 1 & $0.043 \pm 0.011$ & $0.039 \pm 0.012$ & $8.34 \pm 2.15$ & $0.36 \pm 0.16$ & $4.28 \pm 1.10$ \\
\hline 2 & $0.022 \pm 0.002$ & $0.039 \pm 0.013$ & $3.62 \pm 0.26$ & $0.33 \pm 0.08$ & $3.22 \pm 0.78$ \\
\hline 3 & $0.052 \pm 0.014$ & $0.113 \pm 0.016$ & $8.59 \pm 1.54$ & $0.78 \pm 0.07$ & $4.45 \pm 1.41$ \\
\hline 4 & $0.030 \pm 0.006$ & $0.057 \pm 0.014$ & $10.52 \pm 4.18$ & $1.05 \pm 0.32$ & $7.69 \pm 3.00$ \\
\hline 5 & $0.032 \pm 0.002$ & $0.051 \pm 0.010$ & $2.91 \pm 0.71$ & $0.23 \pm 0.04$ & $1.80 \pm 0.62$ \\
\hline 6 & 0.014 & NA & 1.44 & NA & NA \\
\hline 7 & $0.052 \pm 0.003$ & $0.029 \pm 0.010$ & NA & $0.18 \pm 0.07$ & NA \\
\hline 8 & $0.011 \pm 0.005$ & $0.018 \pm 0.004$ & $3.40 \pm 0.70$ & $0.18 \pm 0.05$ & $1.29 \pm 0.01$ \\
\hline 9 & $0.018 \pm 0.003$ & $0.028 \pm 0.004$ & $1.95 \pm 0.34$ & $0.18 \pm 0.03$ & $0.94 \pm 0.12$ \\
\hline Group & $0.031 \pm 0.016$ & $0.045 \pm 0.028$ & $5.50 \pm 3.66$ & $0.40 \pm 0.34$ & $3.37 \pm 2.55$ \\
\hline
\end{tabular}

Table 3. Measurement Repeatability. Intraclass correlation coefficients (ICC) and mean \pm standard deviation coefficients of variation $(\mathrm{CV})$ for oxygen metabolism measured during arterial occlusion and venous occlusion $\left(\mathrm{VO}_{2} \mathrm{AO}\right.$ and $\mathrm{VO} 2 \mathrm{VO}$, respectively), as well as oxygen metabolism index $\left(\mathrm{VO}_{2 \mathrm{i}}\right)$, blood flow measured during venous occlusion (BF), blood flow index $(\mathrm{BFI})$, total hemoglobin concentration $\left(\mathrm{HbT}_{0}\right)$, and oxygen saturation $\left(\mathrm{StO}_{20}\right)$.

\begin{tabular}{ccccccccc}
\hline Repeatability Measure & $\mathbf{V O}_{\mathbf{2 A O}}$ & $\mathbf{V O}_{\mathbf{2 V O}}$ & $\mathbf{V O}_{\mathbf{2 i}}$ & $\mathbf{B F}$ & $\mathbf{B F I}$ & $\mathbf{H b T}_{\mathbf{0}}$ & $\mathbf{S t O}_{\mathbf{2 0}}$ \\
\hline $\mathrm{ICC}$ & 0.88 & 0.85 & 0.77 & 0.83 & 0.62 & 0.99 & 0.99 \\
\hline $\mathrm{CV}$ & $0.19 \pm 0.13$ & $0.24 \pm 0.13$ & $0.24 \pm 0.09$ & $0.27 \pm 0.12$ & $0.25 \pm 0.11$ & $0.06 \pm 0.07$ & $0.03 \pm 0.02$ \\
\hline
\end{tabular}


Results from the linear mixed effect model (LMM) where DCS-measured BFI averaged $15 \mathrm{~s}$ prior to venous occlusion was regressed on NIRS-measured BF (Figure 1) demonstrated a significant positive linear association between BF and BFI (slope $=5.8 \times 10^{-7} ; p=0.06$ ) with a correlation, adjusted for repeated measures, of 0.70 . Significant variation in the subject-specific slope estimates were not observed $(p=0.37)$.

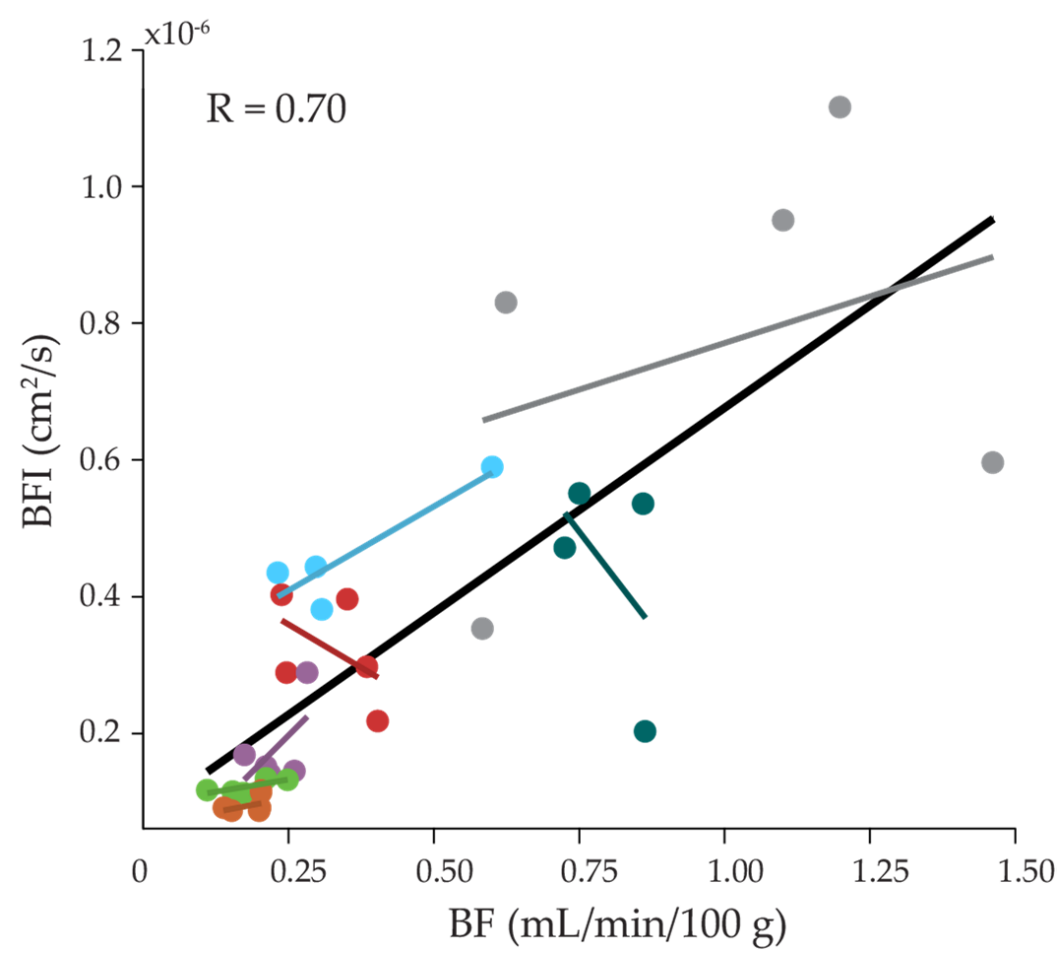

Figure 1. Relationship between NIRS and DCS measured blood flow. Blood flow measured during venous occlusion with NIRS (BF) at $3.5 \mathrm{~cm}$ versus blood flow index measured by DCS averaged $15 \mathrm{~s}$ prior to venous occlusion (BFI). Data are color-coded by participant. The solid black line and indicates the overall linear fit for the group data. Colored lines indicate best linear fits for individual participants.

Results from the $\mathrm{LMM}$ where $\mathrm{VO}_{2 \mathrm{VO}}$ was regressed on $\mathrm{VO}_{2 \mathrm{AO}}$ (Figure $2 \mathrm{~A}$ ) revealed that $\mathrm{VO}_{2 \mathrm{AO}}$ and $\mathrm{VO}_{2 \mathrm{VO}}$ were significantly and positively associated (slope $=0.96, p=0.01$ ) with a correlation, adjusted for repeated measures, of 0.51, even after accounting for significant between-subject variation in the estimated subject-specific slope $(p=0.041)$. Notably, as indicated in the Bland-Altman plot (Figure $2 \mathrm{~B}$ ), $\mathrm{VO}_{2 \mathrm{AO}}$ was generally higher than $\mathrm{VO}_{2} \mathrm{VO}$, and the bias tended to increase as mean $\mathrm{VO}_{2}$ increased, resulting in a poor agreement between the two methods $(\mathrm{CCC}=0.40)$.

Results from the LMM where $\mathrm{VO}_{2 \mathrm{i}}$ averaged $15 \mathrm{~s}$ prior to arterial occlusion was regressed on $\mathrm{VO}_{2 \mathrm{AO}}$ (Figure $3 \mathrm{~A}$ ) demonstrated significant between-subject variation in the estimated subject-specific slope $(p=0.06)$. After accounting for this random variation, we failed to detect a significant association between $\mathrm{VO}_{2 \mathrm{AO}}$ and $\mathrm{VO}_{2 \mathrm{i}}$ (slope $=0.93 \times 10^{-6}$, $p=0.16$ ) with a repeated measures adjusted correlation of 0.62 . Similarly, results from the $\mathrm{LMM}$ where $\mathrm{VO}_{2 \mathrm{i}}$ averaged $15 \mathrm{~s}$ prior to venous occlusion was regressed on $\mathrm{VO}_{2} \mathrm{VO}$ (Figure 3B) demonstrated a significant between-subject variation in the estimated subjectspecific slope parameter $(p=0.09)$. After accounting for this random variation, we failed to detect a significant association between $\mathrm{VO}_{2 \mathrm{AO}}$ and $\mathrm{VO}_{2 \mathrm{i}}$ (slope $=0.25 \times 10^{-6} ; p=0.55$; repeated measures adjusted correlation of 0.41 ). 

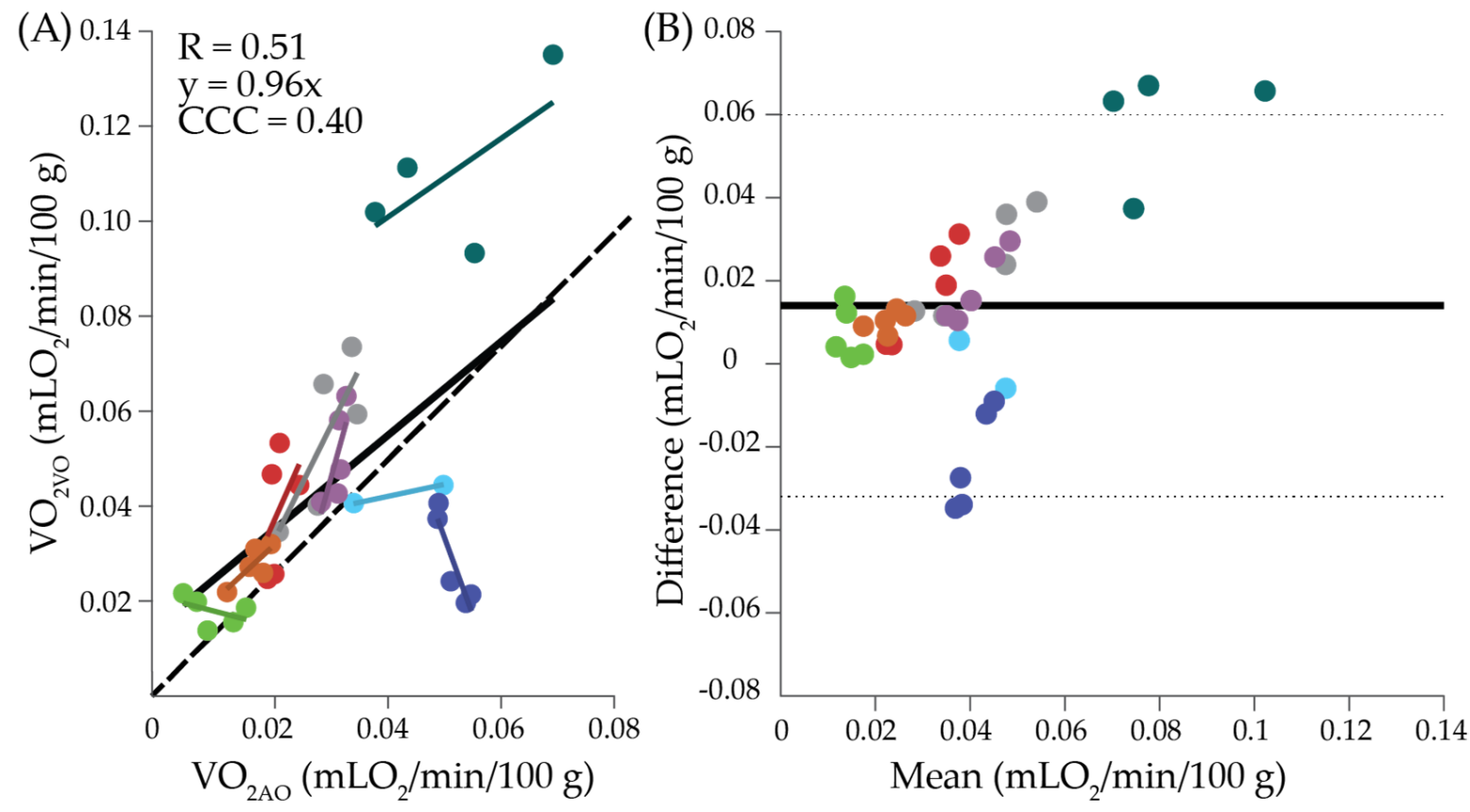

Figure 2. Comparison of oxygen metabolism measured with NIRS during venous and arterial occlusion. (A) Oxygen metabolism measured during arterial occlusion $\left(\mathrm{VO}_{2 \mathrm{AO}}\right)$ versus oxygen metabolism measured during venous occlusion $\left(\mathrm{VO}_{2 \mathrm{VO}}\right)$ at the $3.5-\mathrm{cm}$ source-detector separation. The solid black line indicates the overall linear fit for the group data. Colored lines indicate linear fit for individual participants. The dashed line denotes the line of unity. (B) Bland-Altman plot of the mean of $\mathrm{VO}_{2} \mathrm{AO}$ and $\mathrm{VO}_{2} \mathrm{VO}$ versus the difference. The solid horizontal line indicates the mean difference, and the dotted lines indicate the $95 \%$ limits of agreement. In both figures, data are color-coded by participant.
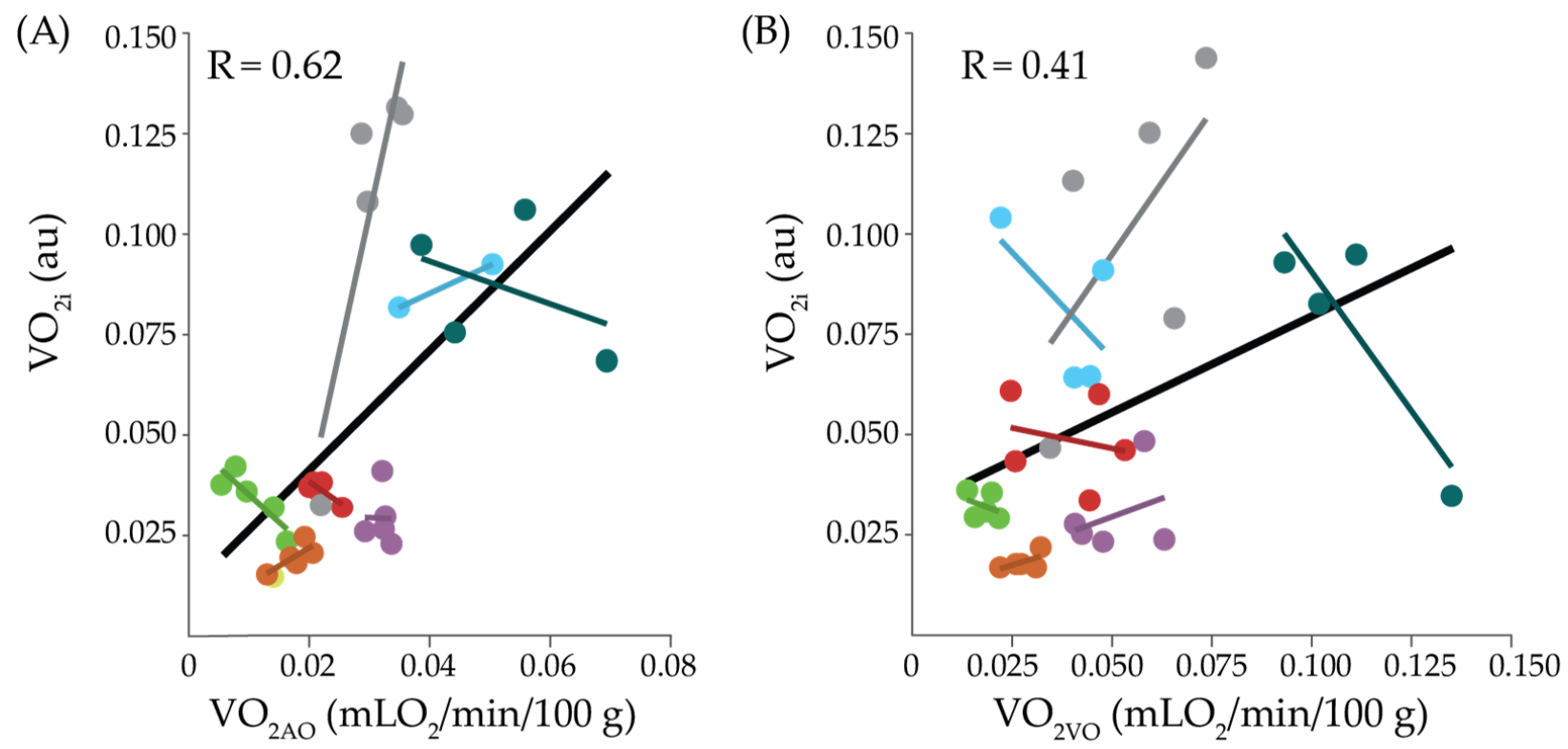

Figure 3. Comparison of oxygen metabolism measured with NIRS versus NIRS + DCS. (A) Oxygen metabolism measured with NIRS during arterial occlusion $\left(\mathrm{VO}_{2 \mathrm{AO}}\right)$ at $3.5 \mathrm{~cm}$ versus NIRS + DCS-measured oxygen metabolism index $\left(\mathrm{VO}_{2 \mathrm{i}}\right)$ averaged $15 \mathrm{~s}$ prior to arterial occlusion. (B) Oxygen metabolism measured with NIRS during venous occlusion $\left(\mathrm{VO}_{2 \mathrm{VO}}\right)$ versus NIRS + DCS-measured oxygen metabolism index $\left(\mathrm{VO}_{2 \mathrm{i}}\right)$, averaged $15 \mathrm{~s}$ prior to venous occlusion; $\mathrm{VO}_{2 \mathrm{i}}$ is in units of $\mathrm{cm}^{2} / \mathrm{s}^{*} \mathrm{mLO}_{2} / \mathrm{g} \times 10^{-6}$. The solid black line and indicates the overall linear fit for the group data. Colored lines indicate linear fit for individual participants. In both figures, data are color-coded by participant. 


\section{Discussion}

In this work we quantified resting oxygen metabolism in the medial gastrocnemius (MG) muscle using 3 different non-invasive, optical methods; two NIRS-only measures taken during a venous and arterial occlusion $\left(\mathrm{VO}_{2} \mathrm{VO}\right.$ and $\mathrm{VO}_{2 \mathrm{AO}}$, respectively), and a combination NIRS + DCS measure averaged $15 \mathrm{~s}$ prior to the venous or arterial occlusion $\left(\mathrm{VO}_{2 \mathrm{i}}\right)$. Using the NIRS-only arterial occlusion method, oxygen metabolism was highest at the $3.5 \mathrm{~cm}$ separation, likely because the contribution from adipose tissue, which has lower metabolism than muscle, is smallest at this separation [21]. Mean oxygen metabolism in the calf at $3.5 \mathrm{~cm}$ was $0.031 \mathrm{mLO}_{2} / \mathrm{min} / 100 \mathrm{~g}$, with a range of values extending from 0.011 to $0.052 \mathrm{mLO}_{2} / \mathrm{min} / 100 \mathrm{~g}$ (Table 2). These values, which were obtained while sitting with leg extended, are similar to previous work performed while supine [15,24], suggesting that resting-state metabolic rate may be independent of posture. Note, previous work did not account for the factor of $\frac{1}{2}$ when calculating $\mathrm{VO}_{2 \mathrm{AO}}$ (Equation (4)), thus our $\mathrm{VO}_{2 \mathrm{AO}}$ values were half those previously reported. All measures of metabolism achieved excellent repeatability, as determined by the intraclass correlation coefficient $>0.75$, and average coefficients of variation were $<0.27$ (Table 3). ICCs were highest and CVs were lowest for the NIRS-only measures at $3.5 \mathrm{~cm}$, presumably because the variable response of adipose tissue to occlusion is minimized [21]. Because the sensor was repositioned in between each epoch, this result suggests that sensor pressure and positioning have minimal influence on our resultant estimation, and this high repeatability agrees well with other publications [15,18,21,22,24].

To our knowledge, this work is the first to investigate the relationship between NIRS + DCS-measured $\mathrm{VO}_{2 \mathrm{i}}$ and the NIRS-measured $\mathrm{VO}_{2 \mathrm{VO}}$ and $\mathrm{VO}_{2 \mathrm{AO}}$ in the muscle. Despite the lack of previous validation, $\mathrm{VO}_{2 \mathrm{i}}$ is often employed as a measure of oxygen metabolism in the muscle. Typically $\mathrm{VO}_{2 \mathrm{i}}$ is first calibrated into physiological units using $\mathrm{VO}_{2 \mathrm{AO}}$ (or, in theory, $\mathrm{VO}_{2 \mathrm{VO}}$ ) $[15,16]$. However, we found no significant correlation between $\mathrm{VO}_{2 \mathrm{i}}$ and $\mathrm{VO}_{2 \mathrm{AO}}(p=0.15$, Figure $3 \mathrm{~A})$, nor between $\mathrm{VO}_{2 \mathrm{i}}$ and $\mathrm{VO}_{2 \mathrm{VO}},(p=0.55$, Figure $3 \mathrm{~B})$. Reasons for the lack of correlation may include inter-participant variations in the assumed fraction of venous blood volume in the interrogated tissue $(\gamma$, Equation (3)), blood hemoglobin concentration (Hgb, Equation (3)), and/or differences in depth sensitivity between $\mathrm{VO}_{2 \mathrm{i}}$ and $\mathrm{VO}_{2 \mathrm{AO}} / \mathrm{VO}_{2} \mathrm{VO}$ estimations. $\mathrm{VO}_{2 \mathrm{i}}$ scales proportionally with $\mathrm{Hgb}$ and inversely with $\gamma$ (Equation (6)); significant inter-participant variations in either $\mathrm{Hgb}$ or $\gamma$ would lead to errors in $\mathrm{VO}_{2 \mathrm{i}}$ and could, in turn, weaken correlations with $\mathrm{VO}_{2 \mathrm{AO}} / \mathrm{VO}_{2 \mathrm{VO}}$. Alternatively, $\mathrm{VO}_{2 \mathrm{i}}$ and $\mathrm{VO}_{2 \mathrm{AO}} / \mathrm{VO}_{2} \mathrm{VO}$ may sample different depths in the tissue. While depth sensitivity of all diffuse optical modalities scales roughly with source-detector separation, the exact depth sensitivity of each measure depends on tissue geometry, optical properties, and the optical modality (i.e., NIRS, DCS). Given that oxygen metabolism of adipose tissue is significantly less than muscle [21], and that the thickness of the adipose tissue layer in the MG can be appreciable and can vary widely between participants (ranging from roughly 0.1-2 cm [34]), differences in depth sensitivity between $\mathrm{VO}_{2 \mathrm{i}}$ and $\mathrm{VO}_{2 \mathrm{AO}} / \mathrm{VO}_{2 \mathrm{VO}}$ could lead to different fractions of signal that arises from adipose tissue versus muscle. Regardless of the reason, the correlation between $\mathrm{VO}_{2 \mathrm{i}}$ and $\mathrm{VO}_{2 \mathrm{AO}} / \mathrm{VO}_{2 \mathrm{VO}}$ shows that the variability in the calibration coefficient between $\mathrm{VO}_{2 \mathrm{i}}$ and $\mathrm{VO}_{2 \mathrm{AO}} / \mathrm{VO}_{2} \mathrm{VO}$ is substantial across participants. Thus, it is preferrable to calibrate $\mathrm{VO}_{2 \mathrm{i}}$ prior to every monitoring session. Important future work is needed to compare $\mathrm{VO}_{2 \mathrm{i}} / \mathrm{VO}_{2 \mathrm{AO}} / \mathrm{VO}_{2 \mathrm{VO}}$ against other gold standard modalities like PET or MRI.

Of note, we also investigated the relationship between $\mathrm{VO}_{2 \mathrm{AO}}$ and $\mathrm{VO}_{2 \mathrm{VO}}$. We found $\mathrm{VO}_{2} \mathrm{VO}$ was significantly correlated with $\mathrm{VO}_{2 \mathrm{AO}}(p=0.01$, Figure $2 \mathrm{~A})$, as has been observed in the forearm $[19,22]$. However, the agreement between the two methods was poor $(C C C=0.40)$, with a significant positive bias. This lack of agreement may be due to the fact that the venous occlusion was always performed prior to the arterial occlusion within each epoch. Because participants were permitted to readjust their legs between epochs, it is possible that $2 \mathrm{~min}$ was not enough time to return to a resting level of oxygen metabolism before the venous occlusion. Alternatively, because participants often reported the desire to 
move their legs to restore circulation at the end of each epoch, it is possible that metabolism dropped over the course of the epoch in response to restricted perfusion. Previous work found a similar reduction in $\mathrm{VO}_{2} \mathrm{VO}$ with successive venous occlusions [22]. To avoid any potential effect of occlusion order, future work should randomize the order of venous and arterial occlusions. Nevertheless, given the moderate correlation between $\mathrm{VO}_{2 \mathrm{AO}}$ and $\mathrm{VO}_{2 \mathrm{VO}}$, these results suggest that venous and arterial occlusion measurements in the MG at these source-detector separations may not be interchangeable.

Finally, we also quantified and compared NIRS- and DCS-measured blood flow (BF and BFI, respectively). Our NIRS-measured blood flow ranged from 0.179 to $1.049 \mathrm{~mL} / \mathrm{min} / 100 \mathrm{~g}$, which is lower than previously reported in the MG while supine $(0.46$ to $1.36 \mathrm{~mL} / \mathrm{min} / 100 \mathrm{~g})$ [15]. This discrepancy is consistent with the known postural dependence of muscle perfusion [35]. While $\mathrm{VO}_{2 \mathrm{i}}$ did not correlate with $\mathrm{VO}_{2 \mathrm{AO}}$ or $\mathrm{VO}_{2 \mathrm{VO}}$, DCS-measured BFI was indeed correlated with NIRS-measured BF ( $p=0.06$, Figure 1). Previous work found a similar correlation between BFI averaged during the venous occlusion and BF in the forearm [33]. In the MG, we found BFI averaged both prior to and during the venous occlusion were correlated with BF, suggesting that blood flow quantified during a venous occlusion reflects the value of blood flow in a non-occluded state. Additionally, BFI had good repeatability $(\mathrm{ICC}=0.62$, mean $\mathrm{CV}=0.25$ ), which further supports the notion that BFI could potentially be used as a surrogate for BF to circumvent the need for venous occlusions to estimate blood flow.

\section{Materials and Methods}

Nine healthy, ambulatory participants $>18$ years were recruited. Subjects were excluded for participation if they had a history of lower extremity joint pain, contractures, major sensory deficits, evidence of orthopedic, muscular, or physical disability, evidence of vestibular, auditory, or proprioceptive impairment, orthostatic hypotension, and/or any neurological insult. All experiments were approved by the Emory University Institutional Review Board. All participants gave informed written consent before participating.

The experimental protocol is outlined in Figure 4. A pressure occlusion tourniquet (Zimmer ATS 2000 Tourniquet System) was affixed to the thigh of the dominant leg just above the knee. Participants were seated with their dominant leg and foot weight supported, and they were instructed to relax to limit hyperextension/enforced extension of the knee for the duration of the protocol. First, baseline measures of resting-state wavelengthdependent absorption and reduced scattering coefficients $\left(\mu_{\mathrm{a}}(\lambda)\right.$ and $\mu_{\mathrm{s}}{ }^{\prime}(\lambda)$, respectively) were made with NIRS by gently holding an optical sensor over the outstretched medial gastrocnemius (MG). Measurements were repeated 3 times, repositioning slightly between each measure to account for local inhomogeneities in the underlying tissue. Next, the optical sensor was secured to the MG using a flexible rubber band. Care was taken to ensure adequate sensor contact with the skin without applying excessive pressure that could induce significant hemodynamic perturbations [36,37]. Continuous monitoring of dynamic changes in hemoglobin concentration (NIRS) and blood flow index (DCS) was performed during a 2-min baseline, a 30-s venous occlusion (VO, $90 \mathrm{mmHg}$ tourniquet pressure), a 2-min recovery, a 30-s arterial occlusion (AO, $250 \mathrm{mmHg}$ tourniquet pressure [15]), and a 5-min recovery period. The sensor was then removed, and participants were allowed to move their leg. This entire protocol was then repeated 5 times for a total of 5 arterial and 5 venous occlusions per measurement session. Upon completion of these 5 epochs, a final NIRS measure of resting-state $\mu_{\mathrm{a}}(\lambda)$ and $\mu_{\mathrm{s}}{ }^{\prime}(\lambda)$ were made by again gently manually holding the sensor over the MG and repositioning 3 times. 


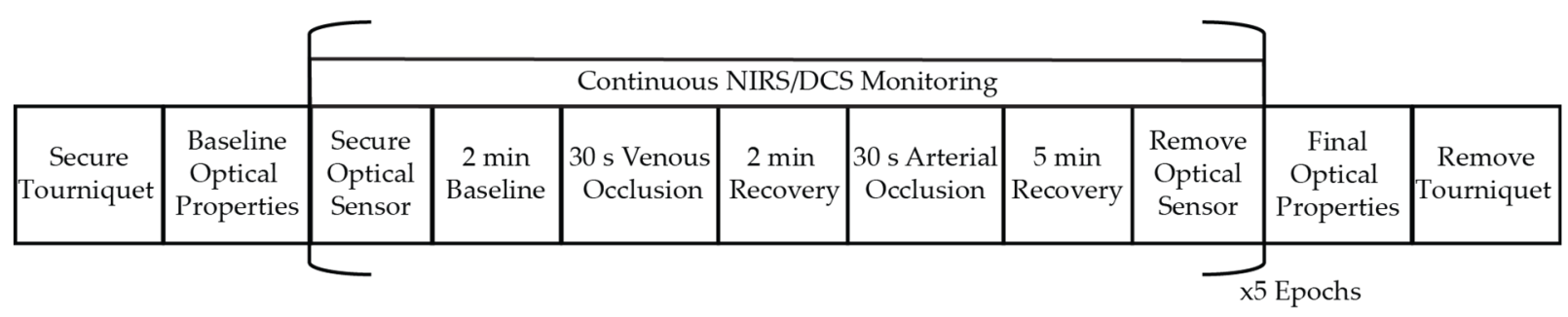

Figure 4. Experimental protocol. First, a tourniquet was secured to the thigh. Participants sat with their leg relaxed to limit hyperextension/enforced extension of the knee. Baseline resting-state optical properties were measured with NIRS by manually holding an optical sensor over the medial gastrocnemius (MG) muscle. Next, the optical sensor was secured to the MG for continuous NIRS/DCS monitoring throughout serial venous and arterial occlusions. This occlusion protocol was repeated 5 times, repositioning the sensor in between each epoch. Upon completion of 5 epochs, a final measure of resting-state optical properties with NIRS was made.

All optical data were acquired using a customized frequency domain NIRS oximeter (Imagent, ISS, Champaign, IL, USA) and an in-house-built DCS system. The NIRS device utilized eight source wavelengths (690, 730, 750, 775, 785, 800, 825, and $830 \mathrm{~nm}$ ) modulated at $110 \mathrm{MHz}$ and four photomultiplier tube detectors with gain modulation of $110 \mathrm{MHz}+5 \mathrm{kHz}$ to achieve heterodyne detection at $5 \mathrm{kHz}$. The DCS device used an $852 \mathrm{~nm}$ long-coherence-length laser source (iBeam Smart, TOPTICA Photonics, Farmington, NY, USA), two four-channel single photon counting modules (SPCMAQ4C-IO, PerkinElmer, Montreal, QC, Canada), and an eight-channel hardware correlator (Flex05-8ch, correlator.com, NJ, USA). NIRS and DCS data were acquired simultaneously ( $21 \mathrm{~Hz}$ NIRS, $1 \mathrm{~Hz}$ DCS) by placing an $842 \mathrm{~nm}$ short pass filter (FF01-842/SP-32-D, Semrock, Rochester, NY, USA) in front of each NIRS detector to mitigate crosstalk of the DCS source on the NIRS detectors.

The participant interface consisted of a custom-made optical sensor containing five source-detector pairs-four for NIRS $(2.0,2.5,3.0$, and $3.5 \mathrm{~cm})$ and one for DCS $(2.5 \mathrm{~cm})$. These separations were chosen to maximize depth penetration while still maintaining adequate signal-to-noise ratio. For NIRS, we used customized $2.5 \mathrm{~mm}$ fiber bundles for both source and detection (50 $\mu \mathrm{m}$ multimode fibers, NA 0.66, FTTIIG23767, Fiberoptics Technology, Pomfret, CT, USA). For DCS, we used a 1-mm source fiber (FT1000EMT, NA 0.39 , ThorLabs, Newton, NJ, USA) and seven single-mode detector fibers (780HP, Thorlabs, Newton, NJ, USA) bundled together at the $2.5-\mathrm{cm}$ separation. The detected autocorrelation curves from these seven detectors were averaged to improved signal-to-noise ratio. All fibers were embedded in a rigid black 3D printed holder.

The data analysis pipeline is outlined in Figure 5 and described in depth in the following sections. Representative data obtained via this analysis pipeline is shown in Figure 6. Measures of participant-specific, wavelength-dependent optical properties $\left(\mu_{\mathrm{a}}(\lambda)\right.$ and $\mu_{s}{ }^{\prime}(\lambda)$ ) were estimated from multi-distance measures of AC attenuation and phase shift using the semi-infinite solution to the photon diffusion equation [38] (Figure 5A). The measured $\mu_{\mathrm{s}}{ }^{\prime}(\lambda)$ were fit to an empirical power law relationship $\mathrm{A} \lambda^{-\mathrm{b}}$, where $A$ is a scaling factor and $b$ is the scattering power. The measured $\mu_{\mathrm{a}}(\lambda)$ were fit to the hemoglobin spectrum to estimate resting-state measures of oxy- and deoxy-hemoglobin concentrations ( $\mathrm{HbR}$ and $\mathrm{HbO}$, respectively), which were used to derive total hemoglobin $(\mathrm{HbT}=\mathrm{HbO}+\mathrm{HbR})$, difference in hemoglobin $(\mathrm{HbD}=\mathrm{HbO}-\mathrm{HbR})$, and tissue oxygen saturation $\left(\mathrm{StO}_{2}=\mathrm{HbO} / \mathrm{HbT}^{*} 100 \%\right)$. Water concentration was assumed to be $75 \%$. We also estimated the wavelength-dependent differential pathlength factor $(\operatorname{DPF}(\lambda))$ that accounts for the increase in photon pathlength due to multiple scattering events using the following formula [39]:

$$
\operatorname{DPF}(\lambda)=\frac{3 \mu_{\mathrm{s}}{ }^{\prime}(\lambda)}{2 \sqrt{3 \mu_{\mathrm{a}}(\lambda) \mu_{\mathrm{s}}{ }^{\prime}(\lambda)+1}}
$$


(A)

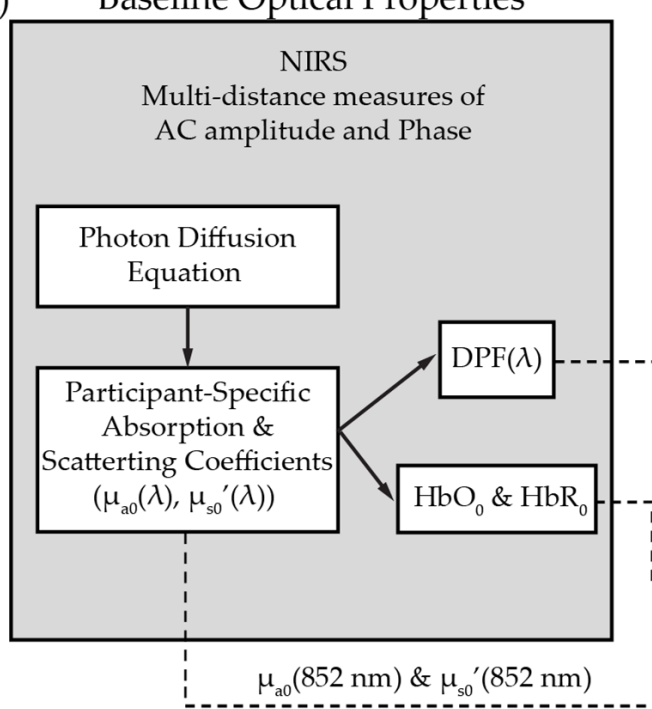

(B) Continuous NIRS/DCS Monitoring

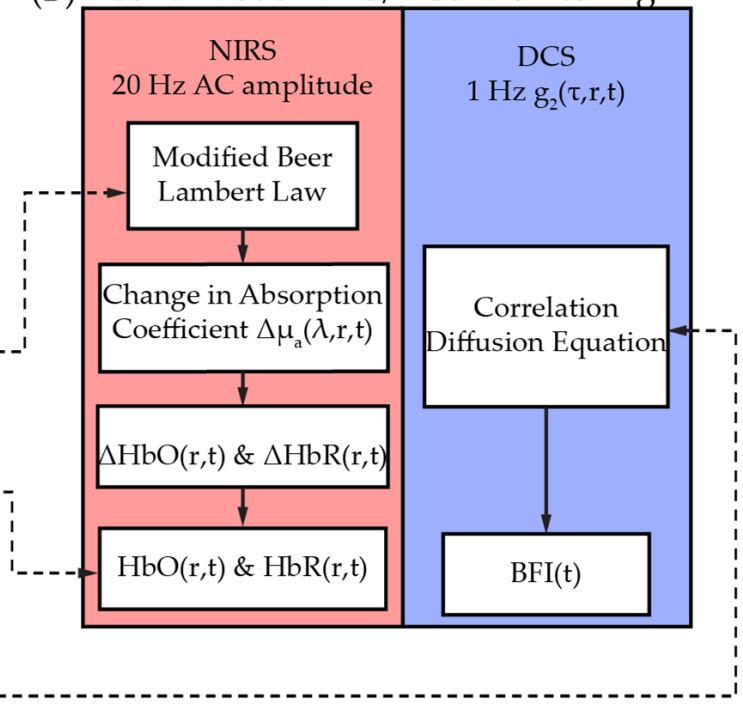

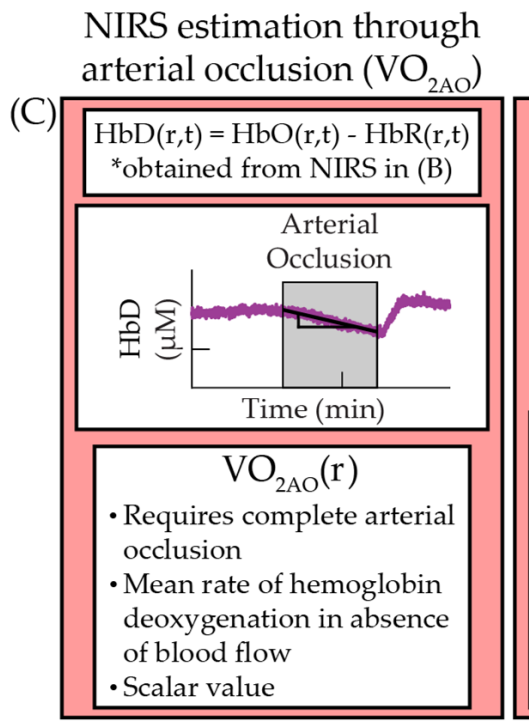

NIRS estimation through venous occlusion $\left(\mathrm{VO}_{2 \mathrm{VO}}\right)$

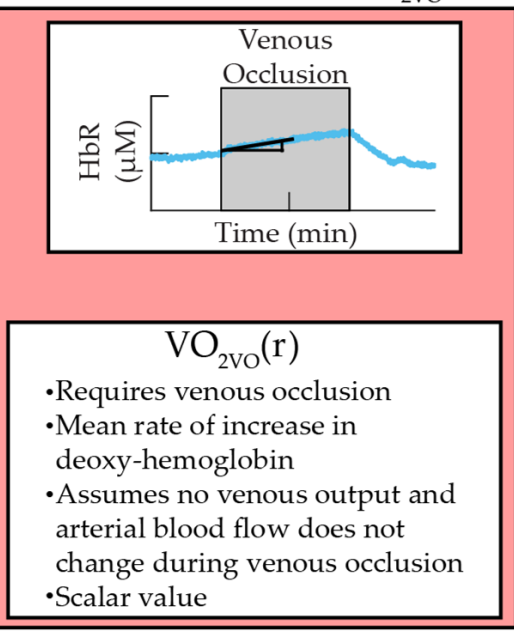

NIRS+DCS estimation through Ficks Law $\left(\mathrm{VO}_{2 \mathrm{i}}\right)$

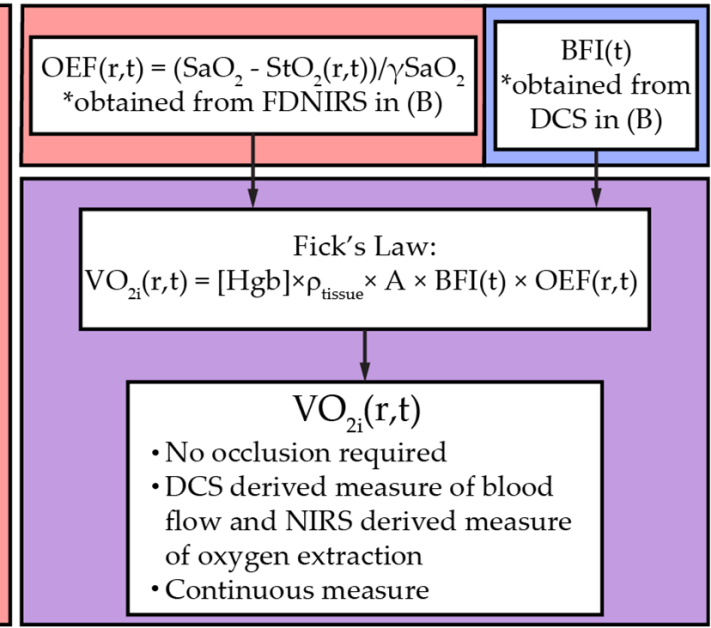

Figure 5. Data analysis pipeline. (A) First, wavelength-dependent optical properties $\left(\mu_{\mathrm{a}}(\lambda)\right.$ and $\left.\mu_{\mathrm{s}}{ }^{\prime}(\lambda)\right)$ were determined using the semi-infinite solution to the photon diffusion equation and were used to estimate baseline hemoglobin concentrations $\left(\mathrm{HbO}_{0}\right.$ and $\left.\mathrm{HbR}_{0}\right)$ and the wavelength-dependent differential pathlength factor $(\operatorname{DPF}(\lambda))$. (B) Next, dynamic changes in hemoglobin concentration were estimated during occlusion epochs with NIRS using the modified Beer-Lambert Law coupled with baseline variables from A (left panel, in red). Dynamic changes in blood flow index were estimated with DCS during occlusion epochs by fitting measured intensity autocorrelation curves to the semi-infinite solution of the correlation diffusion equation using baseline optical properties from A (right panel, in blue). (C) Finally, oxygen metabolism was calculated one of three ways: (1) using the mean rate of hemoglobin deoxygenation at each source-detector separation, $r$, from $\mathrm{B}$ during arterial occlusion $\left(\mathrm{VO}_{2 \mathrm{AO}}(\mathrm{r})\right.$, red box, left); (2) using the mean rate of increase in deoxyhemoglobin at each $\mathrm{r}$ from $\mathrm{B}$ during venous occlusion $\left(\mathrm{VO}_{2} \mathrm{VO}(\mathrm{r})\right.$, red box, middle); (3) using Fick's Law by combining NIRS measures of oxygen extraction from B (red box, left side) and DCS-derived measures of blood flow index from B (blue box, right side) to quantify an index of oxygen metabolism index $\left(\mathrm{VO}_{2 \mathrm{i}}(\mathrm{r}, \mathrm{t})\right.$, purple box $)$. 


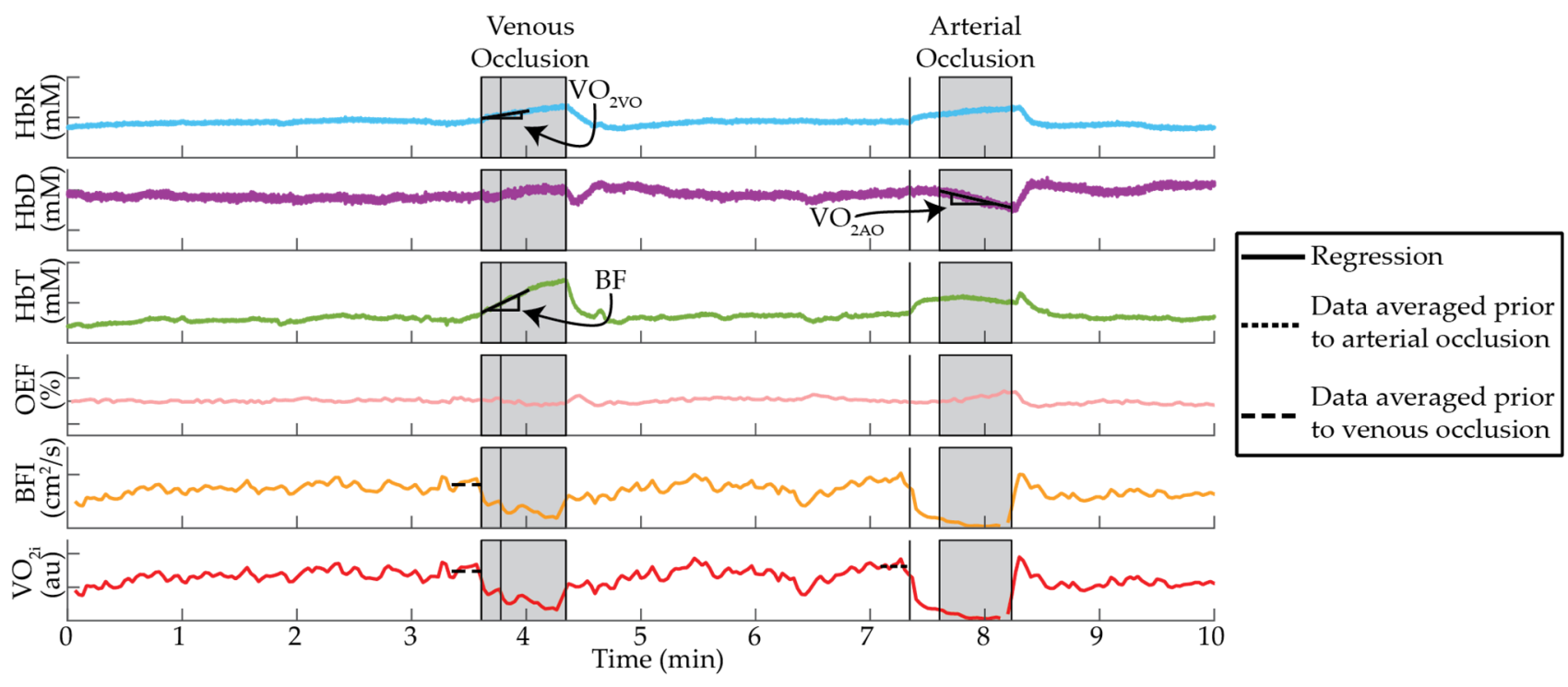

Figure 6. Representative cuff occlusion data. NIRS-measured deoxyhemoglobin ( $\mathrm{HbR})$, hemoglobin difference ( $\mathrm{HbD})$, total hemoglobin $(\mathrm{HbT})$, and oxygen extraction fraction (OEF), along with DCS-measured blood flow index (BFI), and NIRS/DCS measured oxygen metabolism index $\left(\mathrm{VO}_{2 \mathrm{i}}\right.$, in units of $\left.\mathrm{cm}^{2} / \mathrm{s}^{*} \mathrm{mLO}_{2} / \mathrm{g}\right)$ as a function of time during a single occlusion epoch. Shaded regions indicate the venous and arterial occlusions; vertical black lines denote the start of cuff occlusion, the time point when the cuff pressure reached the desired target, and the cuff release. Solid black lines indicate the linear regressions used to quantify NIRS-only measures of blood flow and oxygen metabolism. Dotted lines indicate regions of $\mathrm{BFI}$ and $\mathrm{VO}_{2 \mathrm{i}}$ that were averaged for comparison with NIRS-only measures.

These measurements were made at baseline (3 repetitions), during the 2 -min baseline prior to venous occlusion at the start of each epoch, and upon completion of the 5 epochs (3 repetitions) for a total of 11 values that were averaged to yield a mean resting-state estimate of of $\mu_{\mathrm{a}}(\lambda), \mu_{\mathrm{s}}{ }^{\prime}(\lambda), \mathrm{DPF}(\lambda), \mathrm{A}, \mathrm{b}, \mathrm{HbO}, \mathrm{HbR}, \mathrm{HbT}, \mathrm{HbD}$, and $\mathrm{StO}_{2}$, denoted with subscript 0 .

As outlined in Figure 5B and shown in Figure 6, continuous monitoring of dynamic changes in hemoglobin concentration with NIRS during occlusion epochs were estimated at each source-detector separation using the modified Beer-Lambert Law:

$$
\log \left[\frac{\mathrm{AC}(\lambda, r, t)}{\mathrm{AC}_{0}(\lambda, r)}\right]=\mathrm{r} \times \operatorname{DPF}(\lambda) \times \Delta \mu_{\mathrm{a}}(\lambda, \mathrm{r}, \mathrm{t}) .
$$

where $\operatorname{AC}(\lambda, r, t)$ is the AC amplitude of detected light measured at wavelength $\lambda$, sourcedetector separation, $\mathrm{r}$, and time $\mathrm{t} ; \mathrm{AC}_{0}(\lambda, r)$ is the mean $\mathrm{AC}$ amplitude measured at wavelength $\lambda$ during a 1-min baseline at the beginning of each epoch prior to the venous occlusion; $\operatorname{DPF}(\lambda)$ is the wavelength-dependent differential pathlength factor obtained as described above (Equation (1)). Changes in hemoglobin concentrations $(\Delta \mathrm{HbO}(\mathrm{r}, \mathrm{t})$ and $\Delta \operatorname{HbR}(\mathrm{r}, \mathrm{t}))$ were derived from $\Delta \mu_{\mathrm{a}}(\lambda, \mathrm{r}, \mathrm{t})$ at 690,785 , and $825 \mathrm{~nm}$. Continuous measures of $\mathrm{HbO}(r, t), \operatorname{HbR}(r, t), \mathrm{HbT}(r, t), \mathrm{HbD}(r, t)$, and $\mathrm{StO}_{2}(\mathrm{t})$ were then quantified from these changes and the resting-state estimations obtained as described above (e.g., $\mathrm{HbR}(\mathrm{r}, \mathrm{t})=\mathrm{HbR} 0+\Delta \mathrm{HbR}(\mathrm{r}, \mathrm{t}))$. Additionally, we estimated a continuous measure of oxygen extraction fraction $(\mathrm{OEF})$ :

$$
\operatorname{OEF}(\mathrm{r}, \mathrm{t})=\frac{\mathrm{SaO}_{2}-\mathrm{StO}_{2}(\mathrm{r}, \mathrm{t})}{\gamma * \mathrm{SaO}_{2}} .
$$

Here, $\mathrm{SaO}_{2}$ is the arterial oxygen saturation, and $\gamma$ is the fraction of blood volume within the venous compartment of the tissue interrogated with our sensor [26]. We assumed a constant $\mathrm{SaO}_{2}$ of $100 \%$ and $\gamma$ of 0.675 for all participants $[16,26]$. 
Continuous monitoring of dynamic changes in blood flow with DCS during occlusion epochs was estimated by fitting the measured intensity autocorrelation curves, $g_{2}(\tau, t)$, for a blood flow index $(B F I(t))$ using the semi-infinite solution to the correlation diffusion equation and incorporating the measured resting-state $\mu_{\mathrm{a} 0}$ and $\mu_{\mathrm{s}}{ }^{\prime} 0$ extrapolated for 852 $\mathrm{nm}$ [38]. Fits were constrained to $\mathrm{g}_{2}(\tau, \mathrm{t})>1.05$. Data for a given detector were discarded if the detected photon count rate was less than $5 \mathrm{kHz}$.

Muscle oxygen metabolism $\left(\mathrm{VO}_{2}\right)$ was measured with three distinct approaches (Figures $5 \mathrm{C}$ and 6). The first approach, which we dub $\mathrm{VO}_{2 \mathrm{AO}}$, estimates $\mathrm{VO}_{2}$ (in units of $\mathrm{mLO}_{2} / \mathrm{min} / 100 \mathrm{~g}$ ) using the rate of hemoglobin deoxygenation during arterial occlusion [15-17,19-23]:

$$
\mathrm{VO}_{2 \mathrm{AO}}(\mathrm{r})=4 \times \frac{\mathrm{MW}_{\mathrm{O}_{2}}}{\rho_{\mathrm{O}_{2}} \times \rho_{\text {tissue }}} \times \frac{1}{2} \frac{\mathrm{dHbD}(\mathrm{r}, \mathrm{t})}{\mathrm{dt}} .
$$

Here $\frac{d H b D(r, t)}{d t}$ is the slope of $\mathrm{HbD}(r, t)$ versus time during the arterial occlusion estimated via linear regression using fitlm in MATLAB 2020b. The factor of $\frac{1}{2}$ accounts for the fact that $\mathrm{HbD}$ represents the difference between 2 slopes [40]. The 4 accounts for the $4: 1$ ratio of oxygen to hemoglobin, $\mathrm{MW}_{\mathrm{O} 2}$ is the molecular weight of oxygen $(32 \mathrm{~g} / \mathrm{mol})$, $\rho_{\mathrm{O} 2}$ is the density of oxygen $(1.429 \mathrm{~g} / \mathrm{L})$, and $\rho_{\text {tissue }}$ is the assumed density of the muscle tissue $(1.04 \mathrm{~kg} / \mathrm{L})[16]$.

The second approach, which we dub $\mathrm{VO}_{2 \mathrm{VO}}$, relates oxygen metabolism to the increase in deoxyhemoglobin during the venous occlusion $[18,19,22,24,26]$ :

$$
\mathrm{VO}_{2 \mathrm{VO}}(\mathrm{r})=4 \times \frac{\mathrm{MW}_{\mathrm{O}_{2}}}{\rho_{\mathrm{O}_{2}} \times \rho_{\text {tissue }}} \times \frac{\mathrm{dHbR}(\mathrm{r}, \mathrm{t})}{\mathrm{dt}} .
$$

Here $\frac{d H b R(r, t)}{d t}$ is the slope of $H b R(r, t)$ versus time during the venous occlusion estimated via linear regression. This approach assumes that the arterial input is fully saturated (i.e., $\mathrm{SaO}_{2}=100 \%$ ) [16] such that its contribution to the rate of change of $\mathrm{HbR}$ is negligible. This linear regression was applied over two separate windows. The first window extended from the start of cuff inflation to $25 \mathrm{~s}$ after the start of inflation to account for individuals who had an immediate hemodynamic response to the venous occlusion and thus limit potential accumulation of blood in the venous compartments [23]. The second window extended from when the cuff pressure reached $90 \mathrm{mmHg}$ until the release of pressure to account for individuals who did not have an immediate hemodynamic response suggesting that the venous occlusion was not complete until the desired pressure of $90 \mathrm{mmHg}$ was reached. The window with the greater slope was used to estimate $\mathrm{VO}_{2 \mathrm{VO}}$ for that epoch.

The third approach, which we dubbed $\mathrm{VO}_{2 \mathrm{i}}$, combined the oxygen extraction fraction measured by NIRS with the blood flow index measured by DCS to estimate an index of metabolism using Fick's law [15,16,26,27]:

$$
\mathrm{VO}_{2 \mathrm{i}}(\mathrm{r}, \mathrm{t})=\mathrm{Hgb} \times \rho_{\text {tissue }} \times \mathrm{A} \times \mathrm{BFI}(\mathrm{t}) \times \mathrm{OEF}(\mathrm{r}, \mathrm{t}) .
$$

Here Hgb is the blood hemoglobin concentration (assumed to be $14.1 \mathrm{~g} / \mathrm{dL}$ ) [16], $\rho_{\text {tissue }}$ is the assumed density of the muscle tissue $(1.04 \mathrm{~kg} / \mathrm{L})[16]$, and $\mathrm{A}$ is the amount of oxygen that can bind to hemoglobin $\left(1.34 \mathrm{mLO}_{2} / \mathrm{g} \mathrm{Hb}\right)$. This approach provides a continuous measure of metabolism without the need for vascular occlusions. To compare $\mathrm{VO}_{2 \mathrm{i}}(\mathrm{r}, \mathrm{t})$ with $\mathrm{VO}_{2 \mathrm{AO}}(\mathrm{r})$ and $\mathrm{VO}_{2 \mathrm{VO}}(\mathrm{r}), \mathrm{VO}_{2 \mathrm{i}}(\mathrm{r}, \mathrm{t})$ was averaged over a 15 -s period just prior to the arterial and venous occlusions, respectively.

The venous occlusion also allows us to estimate muscle blood flow (BF) using the mean rate of increase in total hemoglobin concentration during occlusion $[15,16,18,24,33]$. 
We capitalized on this additional information by comparing BF to BFI measured by DCS. We estimated $\mathrm{BF}$ using the following formula:

$$
\mathrm{BF}(\mathrm{r})=\mathrm{MW}_{\mathrm{Hb}} \times \mathrm{Hgb} \times \frac{\mathrm{dHbT}(\mathrm{r}, \mathrm{t})}{\mathrm{dt}} .
$$

Here $\mathrm{MW}_{\mathrm{Hb}}$ is the molecular weight of hemoglobin $(64.458 \mathrm{~g} / \mathrm{mol})[41]$ and $\frac{\mathrm{dHbT}(\mathrm{r}, \mathrm{t})}{\mathrm{dt}}$ is the slope of $\mathrm{HbT}(\mathrm{r}, \mathrm{t})$ versus time estimated via linear regression. Similarly to the calculation of $\mathrm{VO}_{2 \mathrm{VO}}$, the linear regression was applied over two separate windows and the window with the greatest slope was used to estimate BF for that epoch. To compare BF(r) with BFI, $\mathrm{BFI}(\mathrm{t})$ was averaged over a $15 \mathrm{~s}$ period just prior to the venous occlusion, as well as during the full occlusion.

Data were reported as mean \pm standard deviation unless otherwise stated. A Wilcoxon rank sum test was employed to test for sex differences in each measured parameter. A Wilcoxon signed rank test was used to test for differences in $\mathrm{BF}, \mathrm{VO}_{2 \mathrm{AO}}$, and $\mathrm{VO}_{2 \mathrm{VO}}$ between source-detector separations. Linear mixed effect models were used to examine linear relationships between $\mathrm{VO}_{2 \mathrm{i}}$ and $\mathrm{VO}_{2 \mathrm{AO}} / \mathrm{VO}_{2} \mathrm{VO}$, between $\mathrm{BFI}$ and $\mathrm{BF}$, and between $\mathrm{VO}_{2 \mathrm{AO}}$ and $\mathrm{VO}_{2 \mathrm{VO}}$. In these models, because multiple measurements were made on each subject, a subject-specific random slope was modeled in addition to a fixed effect intercept and slope. The significance of between-subject variation in the slope parameter was assessed by examining the significance of the random slope parameter at the 0.1 level of significance. This threshold was chosen based on the small sample size and the number of replicates. After adjusting for repeated measurements and between-subject variation, the fixed effect intercept and slope were examined. Further, we estimated a correlation coefficient $(\mathrm{R})$ to aid in the interpretation of the strength of the linear relationship of the variables of interest in the presence of repeated measures [42]. For the relationship between $\mathrm{VO}_{2 \mathrm{AO}}$ and $\mathrm{VO}_{2 \mathrm{VO}}$, we also used Bland-Altman plots to graphically assess the agreement between the two variables [43] and Lin's concordance correlation coefficient (CCC) to quantify this agreement. The CCC is the product of Pearson's R and a bias correction factor that reflects the degree that the linear association between two variables differs from 45 deg through the origin. Finally, coefficient of variation $(\mathrm{CV}$, defined as the ratio of the standard deviation to the mean across multiple measurements within a single participant) and an intraclass correlation coefficient (ICC) [44,45] were used to assess intra-participant repeatability of all metabolism and blood flow measures, as well as resting-state $\mathrm{HbT}$ and $\mathrm{StO}_{2}$. To estimate ICC, we used a two-way mixed effect, absolute agreement model that assumes experimenters remain fixed across epochs and treats intraparticipant measurements as random samples. Typically, ICC values greater than 0.75 are classified as excellent repeatability, ICC between 0.6 and 0.74 are classified as good repeatability, between 0.4 and 0.59 are classified as fair, and less than 0.4 are classified as poor reliability [45].

Supplementary Materials: The following are available online at https:/ /www.mdpi.com/article/10 .3390/metabo11080496/s1, Table S1: Correlation statistics for all source-detector separations, Table S2: Repeatability of oxygen metabolism and blood flow measurements for all source-detector separations.

Author Contributions: Conceptualization, L.H.T. and E.M.B.; methodology, S.B., B.S., S.E.B., C.M., L.H.T. and E.M.B.; software, S.E.B., S.B., C.M. and E.M.B.; validation, S.E.B.; formal analysis, S.E.B., R.O.B., S.B., C.M. and B.S.; investigation, S.E.B. and R.O.B.; resources, E.M.B.; data curation, S.E.B.; writing-original draft preparation, S.E.B.; writing—review and editing, C.M., E.M.B. and L.H.T.; visualization, S.E.B.; supervision, E.M.B. and L.H.T.; project administration, S.E.B., S.B., B.S. and R.O.B.; funding acquisition, L.H.T., E.M.B., R.O.B. and S.E.B. All authors have read and agreed to the published version of the manuscript.

Funding: This research was funded by NIH R01 HD46922 (L.H.T.) and R21 HL138062 (EMB). This material is additionally based upon work supported by the National Science Foundation Graduate Research Fellowship Program under Grant No. 1937971 (S.E.B. and R.O.B.). Any opinions, findings, 
and conclusions or recommendations expressed in this material are those of the author(s) and do not necessarily reflect the views of the National Science Foundation.

Institutional Review Board Statement: The study was conducted in accordance with the guidelines of the Declaration of Helsinki and approved by the Institutional Review Board of Emory University (IRB00083425, approved 22 April 2016).

Informed Consent Statement: Written informed consent was obtained from all participants involved in the study.

Data Availability Statement: The data presented in this study are available on request from the corresponding author.

Acknowledgments: We would like to acknowledge Wesley Baker and Lucas McKay for fruitful discussion as well as Kyle Cowdrick and Zhou Fang for technical assistance.

Conflicts of Interest: The authors declare no conflict of interest.

\section{References}

1. Dietz, V.; Quintern, J.; Berger, W. Electrophysiological studies of gait in spasticity and rigidityevidence that altered mechanical properties of muscle contribute to hypertonia. Brain 1981, 104, 431-449. [CrossRef] [PubMed]

2. Dietz, V.; Sinkjaer, T. Spastic movement disorder: Impaired reflex function and altered muscle mechanics. Lancet Neurol. 2007, 6, 725-733. [CrossRef]

3. Patrick, S.K.; Denington, A.A.; Gauthier, M.J.A.; Gillard, D.M.; Prochazka, A. Quantification of the UPDRS rigidity scale. IEEE Trans. Neural. Syst. Rehabil. Eng. 2001, 9, 31-41. [CrossRef]

4. Prochazka, A.; Bennett, D.J.; Stephens, M.J.; Patrick, S.K.; Sears-Duru, R.; Roberts, T.; Jhamandas, J.H. Measurement of rigidity in Parkinson's disease. Mov. Disord. 1997, 12, 24-32. [CrossRef] [PubMed]

5. Powell, D.; Hanson, N.; Threlkeld, A.J.; Fang, X.; Xia, R. Enhancement of parkinsonian rigidity with contralateral hand activation. Clin. Neurophysiol. 2011, 122, 1595-1601. [CrossRef]

6. Xia, R.; Powell, D.; Rymer, W.Z.; Hanson, N.; Fang, X.; Threlkeld, A.J. Differentiation between the contributions of shortening reaction and stretch-induced inhibition to rigidity in Parkinson's disease. Exp. Brain Res. 2011, 209, 609-618. [CrossRef]

7. Xu, F.; Ge, Y.; Lu, H. Noninvasive quantification of whole-brain cerebral metabolic rate of oxygen (CMRO2) by MRI. Magn. Reson. Med. 2009, 62, 141-148. [CrossRef]

8. Ferrannini, E. The theoretical bases of indirect calorimetry: A review. Metabolism 1988, 37, 287-301. [CrossRef]

9. Mtaweh, H.; Tuira, L.; Floh, A.A.; Parshuram, C.S. Indirect calorimetry: History, technology, and application. Front. Pediatr. 2018, 6, 257. [CrossRef]

10. Stringer, K.A.; Younger, J.G.; McHugh, C.; Yeomans, L.; Finkel, M.A.; Puskarich, M.A.; Jones, A.E.; Trexel, J.; Karnovsky, A. Whole blood reveals more metabolic detail of the human metabolome than serum as measured by $1 \mathrm{H}-\mathrm{NMR}$ spectroscopy: Implications for sepsis metabolomics. Shock 2015, 44, 200-208. [CrossRef]

11. Basmajian, J.V. Muscles Alive, Their Functions Revealed by Electromyography; Williams \& Wilkins: Baltimore, MD, USA, 1978; ISBN 0-683-00413-1.

12. Nordander, C.; Willner, J.; Hansson, G.-Å.; Larsson, B.; Unge, J.; Granquist, L.; Skerfving, S. Influence of the subcutaneous fat layer, as measured by ultrasound, skinfold calipers and BMI, on the EMG amplitude. Eur. J. Appl. Physiol. 2003, 89, 514-519. [CrossRef]

13. Kuiken, T.A.; Lowery, M.M.; Stoykov, N.S. The effect of subcutaneous fat on myoelectric signal amplitude and cross-talk. Prosthet. Orthot. Int. 2003, 27, 48-54. [CrossRef] [PubMed]

14. Day, S. Important Factors in Surface EMG Measurement; Bortec Biomedical Ltd.: Calgary, AB, Canada, 2002.

15. Henry, B.; Zhao, M.; Shang, Y.; Uhl, T.; Thomas, D.T.; Xenos, E.S.; Saha, S.P.; Yu, G. Hybrid diffuse optical techniques for continuous hemodynamic measurement in gastrocnemius during plantar flexion exercise. J. Biomed. Opt. 2015, 20. [CrossRef]

16. Gurley, K.; Shang, Y.; Yu, G. Noninvasive optical quantification of absolute blood flow, blood oxygenation, and oxygen consumption rate in exercising skeletal muscle. J. Biomed. Opt. 2012, 17, 075010. [CrossRef]

17. De Blasi, R.A.; Cope, M.; Elwell, C.; Safoue, F.; Ferrari, M. Noninvasive measurement of human forearm oxygen consumption by near infrared spectroscopy. Eur. J. Appl. Physiol. 1993, 67, 20-25. [CrossRef]

18. De Blasi, R.A.; Ferrari, M.; Natali, A.; Conti, G.; Mega, A.; Gasparetto, A. Noninvasive measurement of forearm blood flow and oxygen consumption by near-infrared spectroscopy. J. Appl. Physiol. 1994, 76, 1388-1393. [CrossRef] [PubMed]

19. Blasi, R.A.D.; Almenrader, N.; Aurisicchio, P.; Ferrari, M. Comparison of two methods of measuring forearm oxygen consumption (VO2) by near infrared spectroscopy. J. Biomed. Opt. 1997, 2, 171-175. [CrossRef]

20. Hamaoka, T.; Iwane, H.; Shimomitsu, T.; Katsumura, T.; Murase, N.; Nishio, S.; Osada, T.; Kurosawa, Y.; Chance, B. Noninvasive measures of oxidative metabolism on working human muscles by near-infrared spectroscopy. J. Appl. Physiol. 1996, 81, 1410-1417. [CrossRef] 
21. Beekvelt, M.C.P.V.; Borghuis, M.S.; Engelen, B.G.M.V.; Wevers, R.A.; Colier, W.N.J.M. Adipose tissue thickness affects in vivo quantitative near-IR spectroscopy in human skeletal muscle. Clin. Sci. 2001, 101, 21-28. [CrossRef] [PubMed]

22. Van Beekvelt, M.C.P.; Colier, W.N.J.M.; Wevers, R.A.; Van Engelen, B.G.M. Performance of near-infrared spectroscopy in measuring local $\mathrm{O}_{2}$ consumption and blood flow in skeletal muscle. J. Appl. Physiol. 2001, 90, 511-519. [CrossRef] [PubMed]

23. Cheatle, T.R.; Potter, L.A.; Cope, M.; Delpy, D.T.; Smith, P.D.C.; Scurr, J.H. Near-infrared spectroscopy in peripheral vascular disease. Br. J. Surg. 1991, 78, 405-408. [CrossRef]

24. Casavola, C.; Paunescu, L.A.; Fantini, S.; Gratton, E. Blood flow and oxygen consumption with near-infrared spectroscopy and venous occlusion: Spatial maps and the effect of time and pressure of inflation. J. Biomed. Opt. 2000, 5, 269-276. [CrossRef]

25. Homma, S.; Eda, H.; Ogasawara, S.; Kagaya, A. Near-infrared estimation of $\mathrm{O}_{2}$ supply and consumption in forearm muscles working at varying intensity. J. Appl. Physiol. 1996, 80, 1279-1284. [CrossRef]

26. Yu, G.; Durduran, T.; Lech, G.; Zhou, C.; Chance, B.; Mohler, E.R.; Yodh, A.G. Time-dependent blood flow and oxygenation in human skeletal muscles measured with noninvasive near-infrared diffuse optical spectroscopies. J. Biomed. Opt. 2005, 10, 024027. [CrossRef] [PubMed]

27. Tucker, W.J.; Rosenberry, R.; Trojacek, D.; Chamseddine, H.H.; Arena-Marshall, C.A.; Zhu, Y.; Wang, J.; Kellawan, J.M.; Haykowsky, M.J.; Tian, F.; et al. Studies into the determinants of skeletal muscle oxygen consumption: Novel insight from near-infrared diffuse correlation spectroscopy. J. Physiol. 2019, 597, 2887-2901. [CrossRef] [PubMed]

28. Cheung, C.; Culver, J.P.; Takahashi, K.; Greenberg, J.H.; Yodh, A.G. In vivo cerebrovascular measurement combining diffuse near-infrared absorption and correlation spectroscopies. Phys. Med. Biol. 2001, 46, 2053-2065. [CrossRef] [PubMed]

29. Durduran, T.; Yu, G.; Burnett, M.G.; Detre, J.A.; Greenberg, J.H.; Wang, J.; Zhou, C.; Yodh, A.G. Diffuse optical measurement of blood flow, blood oxygenation, and metabolism in a human brain during sensorimotor cortex activation. Opt. Lett. 2004, 29, 1766-1768. [CrossRef]

30. Shang, Y.; Gurley, K.; Symons, B.; Long, D.; Srikuea, R.; Crofford, L.J.; Peterson, C.A.; Yu, G. Noninvasive optical characterization of muscle blood flow, oxygenation, and metabolism in women with fibromyalgia. Arthritis Res. Ther. 2012, 14, R236. [CrossRef]

31. Mesquita, R.C.; Durduran, T.; Yu, G.; Buckley, E.M.; Kim, M.N.; Zhou, C.; Choe, R.; Sunar, U.; Yodh, A.G. Direct measurement of tissue blood flow and metabolism with diffuse optics. Philos. Trans. R. Soc. A Math. Phys. Eng. Sci. 2011, 369, $4390-4406$. [CrossRef]

32. Baker, W.B.; Li, Z.; Schenkel, S.S.; Chandra, M.; Busch, D.R.; Englund, E.K.; Schmitz, K.H.; Yodh, A.G.; Floyd, T.F.; Mohler, E.R. Effects of exercise training on calf muscle oxygen extraction and blood flow in patients with peripheral artery disease. J. Appl. Physiol. 2017, 123, 1599-1609. [CrossRef]

33. Li, Z.; Baker, W.B.; Parthasarathy, A.B.; Ko, T.S.; Wang, D.; Schenkel, S.; Durduran, T.; Li, G.; Yodh, A.G. Calibration of diffuse correlation spectroscopy blood flow index with venous-occlusion diffuse optical spectroscopy in skeletal muscle. J. Biomed. Opt. 2015, 20. [CrossRef] [PubMed]

34. Leahy, S.; Toomey, C.; McCreesh, K.; O’Neill, C.; Jakeman, P. Ultrasound measurement of subcutaneous adipose tissue thickness accurately predicts total and segmental body fat of young adults. Ultrasound Med. Biol. 2012, 38, 28-34. [CrossRef] [PubMed]

35. Amery, A.; Bossaert, H.; Deruyttere, M.; Vanderlinden, L.; Verstraete, M. Influence of body posture on leg blood flow. J. Vasc. Res. 1973, 10, 152-163. [CrossRef]

36. Mosti, G.; Partsch, H. Inelastic bandages maintain their hemodynamic effectiveness over time despite significant pressure loss. J. Vasc. Surg. 2010, 52, 925-931. [CrossRef]

37. Mayrovitz, H.N. Compression-induced pulsatile blood flow changes in human legs. Clin. Physiol. 1998, 18, 117-124. [CrossRef] [PubMed]

38. Durduran, T.; Choe, R.; Baker, W.B.; Yodh, A.G. Diffuse optics for tissue monitoring and tomography. Rep. Prog. Phys. 2010, 73. [CrossRef]

39. Fantini, S.; Hueber, D.; Franceschini, M.A.; Gratton, E.; Rosenfeld, W.; Stubblefield, P.G.; Maulik, D.; Stankovic, M.R. Non-invasive optical monitoring of the newborn piglet brain using continuous-wave and frequency-domain spectroscopy. Phys. Med. Biol. 1999, 44, 1543-1563. [CrossRef]

40. Barstow, T.J. Understanding near infrared spectroscopy and its application to skeletal muscle research. J. Appl. Physiol. 2019, 126, 1360-1376. [CrossRef]

41. Billett, H.H. Hemoglobin and hematocrit. In Clinical Methods: The History, Physical, and Laboratory Examinations; Walker, H.K., Hall, W.D., Hurst, J.W., Eds.; Butterworths: Boston, MA, USA, 1990; ISBN 978-0-409-90077-4.

42. Hamlett, A.C.; Ryan, L.; Wolfinger, R. On the use of PROC MIXED to estimate correlation in the presence of repeated measures. Proc. Stat. Data Anal. 2004, 198, 29.

43. Bland, J.M.; Altman, D. Statistical methods for assessing agreement between two methods of clinical measurement. Lancet 1986, 327, 307-310. [CrossRef]

44. Koo, T.K.; Li, M.Y. A Guideline of selecting and reporting intraclass correlation coefficients for reliability research. J. Chiropr. Med. 2016, 15, 155-163. [CrossRef] [PubMed]

45. Cicchetti, D.V. Guidelines, criteria, and rules of thumb for evaluating normed and standardized assessment instruments in psychology. Psychol. Assess. 1994, 6, 284-290. [CrossRef] 